Article

\title{
Insights into Metal Oxide and Zero-Valent Metal Nanocrystal Formation on Multiwalled Carbon Nanotube Surfaces during Sol-Gel Process
}

\author{
Dipesh Das ${ }^{1}$, Indu V. Sabaraya ${ }^{1}$, Tara Sabo-Attwood ${ }^{2}$ and Navid B. Saleh ${ }^{1, *}$ \\ 1 Department of Civil, Architectural and Environmental Engineering, The University of Texas at Austin, \\ Austin, TX 78712, USA; dipesh.das@utexas.edu (D.D.); indu.venu@utexas.edu (I.V.S.) \\ 2 Department of Environment and Global Health, University of Florida, Gainesville, FL 32610, USA; \\ sabo@phhp.ufl.edu \\ * Correspondence: navid.saleh@utexas.edu; Tel.: +1-(512)-471-9175
}

Received: 12 May 2018; Accepted: 29 May 2018; Published: 5 June 2018

\begin{abstract}
Carbon nanotubes are hybridized with metal crystals to impart multifunctionality into the nanohybrids (NHs). Simple but effective synthesis techniques are desired to form both zero-valent and oxides of different metal species on carbon nanotube surfaces. Sol-gel technique brings in significant advantages and is a viable technique for such synthesis. This study probes the efficacy of sol-gel process and aims to identify underlying mechanisms of crystal formation. Standard electron potential (SEP) is used as a guiding parameter to choose the metal species; i.e., highly negative SEP (e.g., Zn) with oxide crystal tendency, highly positive SEP (e.g., Ag) with zero-valent crystal-tendency, and intermediate range SEP (e.g., $\mathrm{Cu}$ ) to probe the oxidation tendency in crystal formation are chosen. Transmission electron microscopy and X-ray diffraction are used to evaluate the synthesized NHs. Results indicate that SEP can be a reliable guide for the resulting crystalline phase of a certain metal species, particularly when the magnitude of this parameter is relatively high. However, for intermediate range SEP-metals, mix phase crystals can be expected. For example, $\mathrm{Cu}$ will form $\mathrm{Cu}_{2} \mathrm{O}$ and zero-valent $\mathrm{Cu}$ crystals, unless the synthesis is performed in a reducing environment.
\end{abstract}

Keywords: nanohybrid; hybridization; standard electron potential; crystal phase; reducing agents

\section{Introduction}

Carbon nanotube-metal nanohybrids (NHs) are being considered for large scale use as electroand photo-catalysts [1] and are studied for electronics [2], gas sensing [3], biosensing [4], and laser [5] applications. With the increased commercial value, the bulk synthesis of these NHs is attracting interest. A simple sol-gel technique can be a viable process that can produce 100s of mg of multiwalled carbon nanotube (MWNT)-metal NHs [6]. Both zero-valent and oxides of metals can be formed on MWNT surfaces. However, the choice of the metal and its inherent electronic properties will dictate the resulting crystalline phases. Since preserving the oxidation state of the metal crystals is crucial to render their reactive properties $[7,8]$, understanding the mechanism of nanocrystal formation with a particular crystal phase is thus necessitated.

When preparing metallic nanomaterials, achieving a high degree of crystallinity (of the synthesized materials) is essential to extract the desired optical, electronic, and chemical properties [9]. The rate of nucleation during crystal formation on a surface is a strong function of the surface energy as well as the thermodynamic driving force. The former (i.e., the surface energy) is influenced by the surface moieties (e.g., carboxyl groups on crystalline or polymeric [10-12] materials), and the latter (i.e., the thermodynamic driving force) [13], which is described as the difference in Gibbs free energy between the crystal phase and the surrounding liquid, is a function of 
the precursor amount present during synthesis. Thus, the synthesis methods and operating conditions (e.g., temperature [14], reducing agent [15], and precursor amount [13]) are critical elements that need to be adjusted appropriately for the preparation of metal nanocrystals with a high degree of crystallinity [14] and a desired redox state in the metal species [16]. Calcination can facilitate the preparation of ordered structures, but the feasibility of applying such a high temperature of $500{ }^{\circ} \mathrm{C}$ or higher can be limited when carbon nanotubes are involved in the mix [6,17]. The chemical attachment of metallic nanocrystals can facilitate MWNT oxidation and lower the MWNT oxidation temperature via the chemical modification of the MWNT surface. [6] However, such processes are conducive to oxide formation; hence, synthesizing zero-valent nanocrystals can be challenging.

In sol-gel synthesis, strong reducing agents (e.g., borohydride salts) are typically added to form zero-valent nanocrystals $[15,18]$. However, the addition of reducing agents drives the reaction toward zero-valent metal formation (rather than chemical attachment), which leads to isolated and unassociated (from MWNTs) nanocrystal formation. The excess unassociated metal particles then require rigorous post-treatment of the materials to separate the $\mathrm{NHs}$ from the unattached nanocrystals. Furthermore, some of the metals, because of the elemental electron properties, present further challenges in zero-valent metal crystal formation.

The standard electron potential (SEP) of a metal species can dictate the reaction pathway, and hence can control the oxidation state (i.e., metal vs. metal oxide) of the crystal grown on MWNT surfaces. SEP values represent electron transfer capabilities between the oxidized and the zero-valent metal forms (i.e., $\mathrm{M}^{n+}+\mathrm{Ne}^{-} \leftrightarrow \mathrm{M}$, where $\mathrm{M}$ is the metal species and $n$ is the number of electrons involved in the exchange). Literature evidence suggests that metals with negative SEP preferentially form oxides while those with positive values tend to form zero-valent forms of the same. Metal species that are commonly reported to form oxides on carbon nanotube surfaces possess strongly negative SEP values (Table S1). The following oxides are reported to have formed with metals: $\mathrm{Al}_{2} \mathrm{O}_{3}$ [19-21], $\mathrm{CeO}_{2}$ [22,23], $\mathrm{CoO}_{3}$ [24,25], $\mathrm{Eu}_{2} \mathrm{O}_{3}$ [26,27], $\mathrm{Fe}_{\mathrm{x}} \mathrm{O}_{\mathrm{y}}$ [28-31], $\mathrm{HfO}_{2}$ [32,33], $\mathrm{MgO}$ [34], $\mathrm{MoO}_{2}$ [35], $\mathrm{NiO}$ [36], $\mathrm{SiO}_{2}$ [37-39], $\mathrm{SnO}_{2}$ [40], $\mathrm{TiO}_{2}$ [41,42], $\mathrm{V}_{\mathrm{x}} \mathrm{O}_{\mathrm{y}}$ [43], $\mathrm{ZnO}$ [44], and $\mathrm{ZrO}_{2}$ [45]. On the other hand, $\mathrm{Ag}$ [46], $\mathrm{Au}$ [47], $\mathrm{Pt}$ [48], and Pd [49] with a positive SEP are reported to form zero-valent metals on Carbon Nanotube (CNT) surfaces. $\mathrm{Cu}$ and $\mathrm{W}$ (with positive SEP) and Fe (with negative SEP) are exceptions to this trend; i.e., despite their positive SEP values, $\mathrm{Cu}$ [50] and $\mathrm{W}$ [51] are shown to form oxides, whereas Fe with a negative SEP can form zero-valent metal nanocrystals [52]. The challenge, however, is to comment on the role of SEP on forming zero-valent vs. oxide crystals when the sol-gel method is employed to synthesize MWNT-based NHs.

This article aims to evaluate the efficacy of sol-gel process for in situ formation of metal vs. metals oxides onto MWNT surfaces with no extra addition of reducing or oxidizing agents. The study judiciously choses three metal species, namely $\mathrm{Zn}, \mathrm{Ag}$, and $\mathrm{Cu} ; \mathrm{Zn}$ and $\mathrm{Ag}$ has strong negative and positive SEP values ( $\mathrm{Zn}$ with $-0.763 \mathrm{~V}$ and $\mathrm{Ag}$ with $+0.799 \mathrm{~V}$ SEP values), respectively, while $\mathrm{Cu}$ lies in the positive range, but with a much lower magnitude (SEP of $+0.345 \mathrm{~V}$ ) compared to Ag. Transmission electron microscopy is used to evaluate the NH morphology, while X-ray diffraction (XRD) is utilized to characterize the materials before and after calcination. The design of the study is carefully carried out (e.g., synthesizing and characterizing in absence of air to avoid oxidation) and tests the efficacy of sol-gel method to form nanocrystals with both types of crystal phases.

\section{Materials and Methods}

\subsection{Chemicals and Reagents}

Pristine MWNTs (O.D. 8-15 nm) were procured from Cheap Tubes Inc. (Brattleboro, VT, USA). Concentrated nitric acid, sulfuric acid, and copper (II) nitrate monohydrate were purchased from Sigma Aldrich (St. Louis, MO, USA). Trace metal grade silver nitrate was purchased from Alfa Aesar (Haverhill, MA, USA). Isopropanol and dimethylformamide (DMF) were obtained from Fisher Scientific (Pittsburgh, PA, USA) while zinc (II) nitrate hexahydrate was purchased from J.T Baker 
(Center Valley, PA, USA). For preparing all aqueous suspensions and solutions, $18.2 \mathrm{~m} \Omega$ (Milli-Q) water was used unless otherwise stated.

\subsection{Nanohybrid Synthesis}

All materials were synthesized using a modified sol-gel method [6]. In brief, MWNTs (1 g) were acid-etched by ultrasonication (Qsonica LLC, Newtown, CT, USA) in $300 \mathrm{~mL}$ of concentrated nitric and sulfuric acid mixture (1:1 volume basis). Upon sonication, the mixture was refluxed at $100{ }^{\circ} \mathrm{C}$ for $3 \mathrm{~h}$ under continuous stirring. The oxidized MWNTs were subsequently filtered until the $\mathrm{pH}$ of the filtrate reached $>5.5$ and then were dried for $48 \mathrm{~h}$ in a desiccator. After drying, the oxidized MWNTs were re-suspended in isopropanol with an ultrasonic dismembrator (Qsonica, Newtown, CT, USA) and transferred into a round bottom flask. Appropriate amounts, i.e., $123 \mathrm{mg}$ of $\mathrm{Zn}, 85 \mathrm{mg}$ of $\mathrm{Cu}$ and $71 \mathrm{mg}$ of Ag precursors, were added to $10 \mathrm{~mL}$ of isopropanol and introduced drop wise to the MWNT-isopropanol suspension at $0.301 \mathrm{~mL} / \mathrm{min}$ with a peristaltic pump (Ismatec, Wertheim, Germany). The slow rate of precursor addition was maintained to provide sufficient mixing time. The entire suspension was refluxed at $80^{\circ} \mathrm{C}$ for $3 \mathrm{~h}$ in a nitrogen environment. Water was added drop wise into the reaction vessel to promote hydrolysis, where necessary. Afterwards, the refluxed mixture was washed 4 times with isopropanol (as a purification step), which removed any unreacted reagent. Finally, isopropanol was evaporated, the dry materials were powdered using a mortar and pestle, and the resultant materials were calcined at $400{ }^{\circ} \mathrm{C}$ for $3 \mathrm{~h}$ under nitrogen to facilitate crystal formation.

\subsection{Physical Morphology and Elemental Composition}

The physical morphology of the NMs was determined using a JEOL 2010F high resolution transmission electron microscopy (HRTEM, JEOL, Tokyo, Japan) equipped with energy dispersive spectroscopy (EDS). Electron micrographs were obtained at an acceleration voltage of $200 \mathrm{kV}$. The details of the HRTEM methodology are described elsewhere [6,53-59]. In brief, drops of aqueous dispersions of NHs were placed on lacey carbon coated copper TEM grids (SPI Supplies, West Chester, PA, USA) and air-dried over a few minutes. Several micrographs were taken to obtain representative images.

The elemental composition of the dry MWNT and NH samples was evaluated with a Kratos X-ray Photoelectron Spectrometer-Axis Ultra DLD, equipped with a monochromated $\mathrm{Al} \mathrm{K} \mathrm{K}_{\alpha} \mathrm{X}$-ray source $(1.486 \mathrm{KeV})$ and a concentric hemispherical analyzer [6]. A thin layer of powdered sample was placed on a double-sided copper taped stainless steel bar. The bar was then placed in the analysis chamber and degassed for at least $3 \mathrm{~h}$. The X-ray photoelectron spectroscopy (XPS) analysis was then performed to obtain the survey spectra as well as the spatial high-resolution spectra and the data was analyzed by fitting the high-resolution element specific peaks with CasaXPS software (Version 2.3.19). To ensure reproducibility and overall homogeneity, a total of 9 samples for each material (MWNT and three NHs) were analyzed (3 samples each in triplicate batches for all NHs).

\subsection{Analysis of Crystallinity}

The crystallinity of the metal oxide (MO) on the NH surfaces was evaluated with an XRD. A 600 W Rigaku MiniFlex 600 (Rigaku, Tokyo, Japan) with a Cu-K $\alpha$ irradiator ( $0.154 \mathrm{~nm}$ wavelength) and a graphite monochromator was used at a step width of $0.02^{\circ}$ (between $2 \theta$ values of $20^{\circ}$ to $60^{\circ}$ ) and a scanning rate of $2^{\circ} / \mathrm{min}$. For MWNT-Cu/ $\mathrm{Cu}_{2} \mathrm{O}$ samples, the samples were inserted into an airtight XRD sample holder under vacuum before their measurement. This method for the XRD of MWNT- $\mathrm{Cu} / \mathrm{Cu}_{2} \mathrm{O}$ samples was carried out in order to eliminate air exposure of the materials while performing $\mathrm{XRD}$ on them. The scattering was detected using a scintillation counter.

\subsection{Measuring Oxidation-Reduction Potentials (ORPs)}

ORPs were measured with a portable ultrameter (Myron L Company, Carlsbad, CA). Two reaction mixtures, i.e., $\mathrm{MWNT}+$ isopropanol $+\mathrm{Cu}\left(\mathrm{NO}_{3}\right)_{2} \cdot \mathrm{H}_{2} \mathrm{O}$ and $\mathrm{MWNT}+\mathrm{DMF}+\mathrm{Cu}\left(\mathrm{NO}_{3}\right)_{2} \cdot \mathrm{H}_{2} \mathrm{O}$ were 
heated to $70{ }^{\circ} \mathrm{C}$ for $1 \mathrm{~h}$. After calibrating the ultrameter, $1 \mathrm{~mL}$ of the samples was placed in the ORP measurement chamber separately and the ORP was recorded.

\section{Results and Discussion}

\subsection{Physical Morphology and Composition}

Representative TEM micrographs of the NHs show tubular structures with spherical features (darker contrast) on the tubes (Figure 1). The higher magnification images (i.e., Figure $1 \mathrm{~b}, \mathrm{~d}, \mathrm{f}$ ) show lattice fringes on the sphere-like features, indicating crystalline structures, while the exterior walls of the MWNTs are also observed in these images. The size of the nanocrystals is found to be larger for both the oxides (i.e., $8-10 \mathrm{~nm}$ for $\mathrm{ZnO}$ and 5-8 $\mathrm{nm}$ for $\mathrm{Cu}_{2} \mathrm{O}$ ); the zero-valent crystals are smaller (i.e., 2-4 nm) and also are higher in density on the MWNT-Ag NH surfaces. These features are found to be distributed along the tubes. The composition of the samples is quantified with XPS, which indicates a stronger presence of the zero-valent metal compared to the oxides (Table S2).
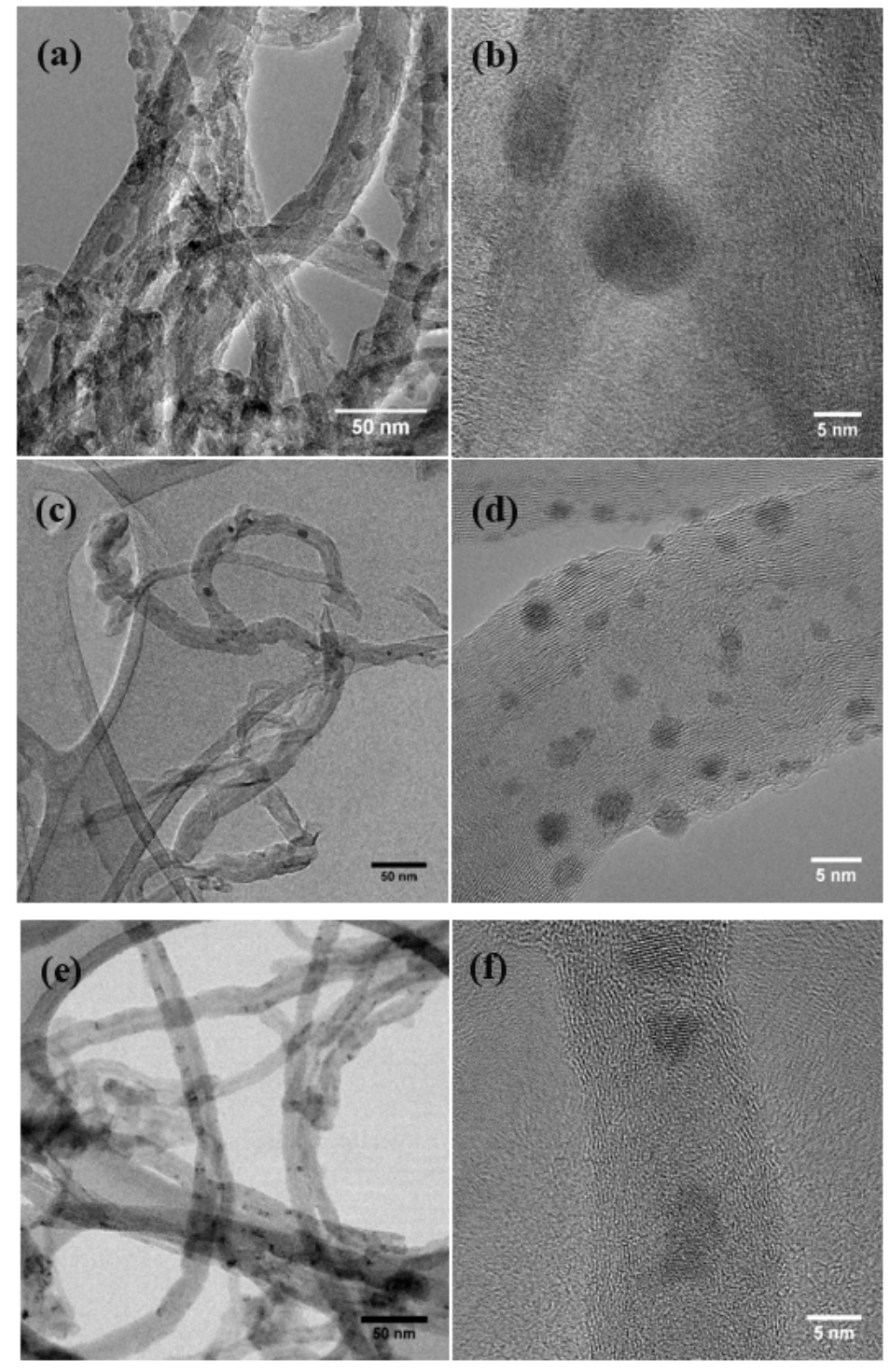

Figure 1. Representative TEM micrographs of $(\mathbf{a}, \mathbf{b})$ multiwalled carbon nanotube (MWNT)-ZnO, (c,d) MWNT-Ag, and (e,f) MWNT-Cu/Cu $2 \mathrm{O}$ nanohybrids (NHs). High-resolution images are shown in $(\mathbf{b}, \mathbf{d}, \mathbf{f})$. 


\subsection{Chemical Attachment of Zn onto MWNTs: Hydroxide to Oxide Formation Pathway}

Nanocrystals growth on the MWNT surfaces was promoted by the negatively charged oxygen moieties on MWNT surfaces. Electrostatic attraction between metal cations and anionic surface moieties on MWNTs associate the $\mathrm{Zn}^{2+}$ with the MWNT surfaces. These ions then react with water molecules (generated from the hydrated zinc nitrate salt) to form $\mathrm{Zn}(\mathrm{OH})_{2}$ on the MWNT surfaces, which serve as nucleation sites for further growth of amorphous and mixed-phased $\mathrm{Zn}(\mathrm{OH})_{2}$ and $\mathrm{ZnO}$. Nanocrystal formation pathway for MWNT-ZnO is evaluated in this study with XRD characterization on the materials, before and after calcination (Figure 2). XRD spectra before calcination shows evidence of both the crystal phases (Figure 2a). During calcination at elevated temeperature (at $400{ }^{\circ} \mathrm{C}$ in this case), the $\mathrm{Zn}(\mathrm{OH})_{2}$ likely loses the excess water and gets converted to $\mathrm{ZnO}$ crystal phases. XRD spectrum on the NH after calcinaton shows no evidence of $\mathrm{Zn}(\mathrm{OH})_{2}$ phase (Figure $1 \mathrm{~b}$ ) and confirms this likely crystal formation pathway. Literature reports on XRD patterns for amorphous $\mathrm{Zn}(\mathrm{OH})_{2}$ and $\mathrm{ZnO}$ are used to relate peak positions with specific crystalline planes [60]. The likely reaction pathway for MWNT-ZnO NH formation is shown below, which is similar to crystal formation pathway described for $\mathrm{TiO}_{2}$ growth on MWNTs [41].

$$
\begin{gathered}
\mathrm{O}-\mathrm{MWNT}^{-} \stackrel{\mathrm{Zn}\left(\mathrm{NO}_{3}\right)_{2}}{\rightarrow} \mathrm{O}-\mathrm{MWNT}^{-} \mathrm{Zn}^{2+} \stackrel{\mathrm{H}_{2} \mathrm{O}}{\rightarrow} \mathrm{MWNT}-\mathrm{ZnO} / \mathrm{Zn}(\mathrm{OH})_{2}(\text { amorphous }) \\
\stackrel{\text { Heat }}{\rightarrow} \mathrm{MWNT}-\mathrm{ZnO}(\text { crystalline })
\end{gathered}
$$

\subsection{Zero-Valent Metal Formation on MWNTs with no Reducing Agent}

MWNT surfaces have successfully been enhanced with zero-valent Ag (with SEP of +0.799 ) crystals, employing the modified sol-gel method. It is noteworthy that no additional reducing agent was required for this synthesis. The XRD spectrum of the MWNT-Ag NH (Figure 3) shows defined peaks at (111), (200), (220), and (311) crystal planes, which correspond to zero-valent Ag [61]. Earlier studies on large-scale MWNT-Ag synthesis though report high quantity of Ag-attachment to MWNTs, the XRD spectrum show less-defined peaks, compared to the results presented in this study [46]. Though this study formed Ag-crystals on poly(acrylic acid)-modified MWNT surfaces, thus the underlying mechanism of these nanocrystal growth is likely quite different compared to those grown on oxidized carbon surfaces.

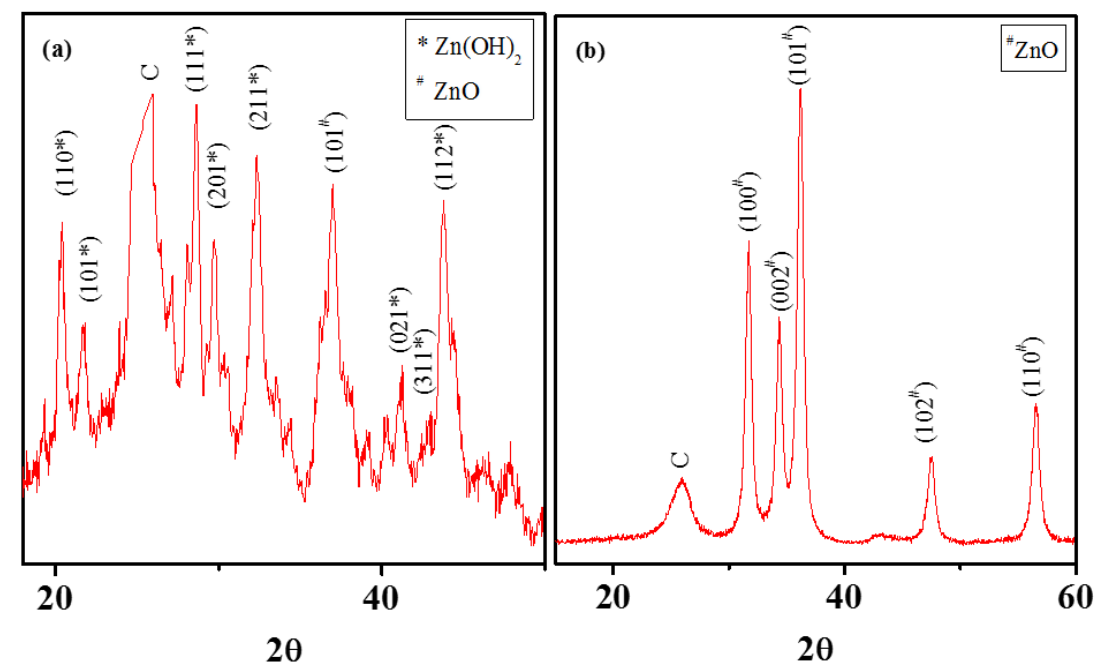

Figure 2. Representative XRD spectra of MWNT-ZnO NH (a) before and (b) after calcination at $400{ }^{\circ} \mathrm{C}$ for $3 \mathrm{~h}$. The peak positions are labeled to indicate the respective crystal planes. The XRD spectra were collected at a scanning rate of $2^{\circ} / \mathrm{min}$. 


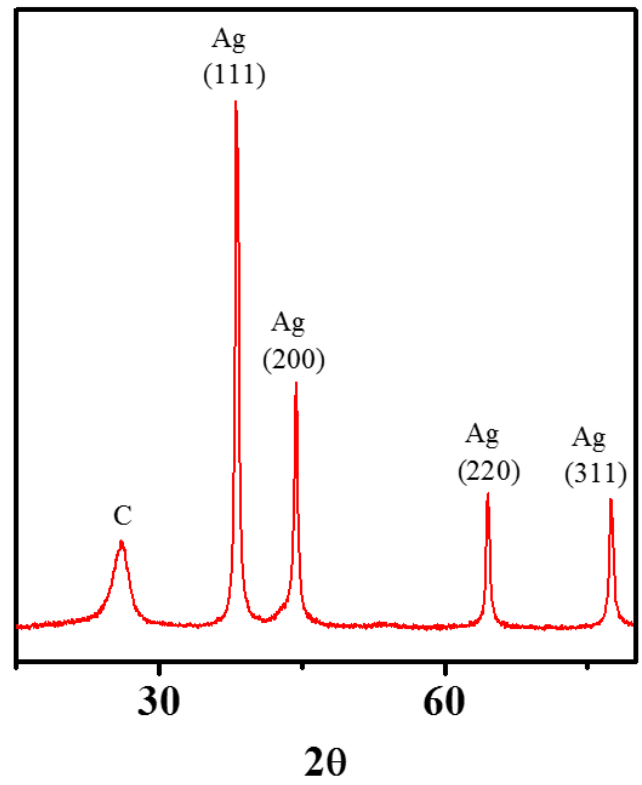

Figure 3. Representative XRD spectra of CNT-Ag NHs. The peak positions are labeled to indicate the respective crystal planes. The spectrum was collected at a scanning rate of $2^{\circ} / \mathrm{min}$.

\subsection{Intermediate SEP-Metal Cu: The Anomaly That Forces Oxide Formation}

With a positive SEP value, much like $\mathrm{Ag}$, $\mathrm{Cu}$ should form zero-valent metals. However, $\mathrm{Cu}$ exhibits anomalous character and produces oxides during chemical attachment with MWNTs. This section attempts to overcome such oxide-forming propensity by using anoxic synthesis and characterization conditions, and results continue to be surprising. Following similar synthesis conditions (when compared to $\mathrm{Zn}$ and $\mathrm{Ag}$ ), the $\mathrm{Cu}$ attachment resulted in a mixed $\mathrm{Cu}$ and $\mathrm{Cu}_{2} \mathrm{O}$ phases as shown in the XRD spectrum (Figure 4a). Defined peaks at (111) and (200) planes (representing zero-valent $\mathrm{Cu}$ ) and at (220) and (111) (representing $\mathrm{Cu}_{2} \mathrm{O}$ phase) are consistent with the reported literature [62]. Literature reports on nano-scale zero-valent copper suggest that such behavior can stem from unavoidable oxidation during XRD characterization [50,51]. Some literature evidences also suggest that such $X R D$ patterns are typical for $\mathrm{Cu} / \mathrm{Cu}_{2} \mathrm{O}$ core/shell nanocrystals [62].

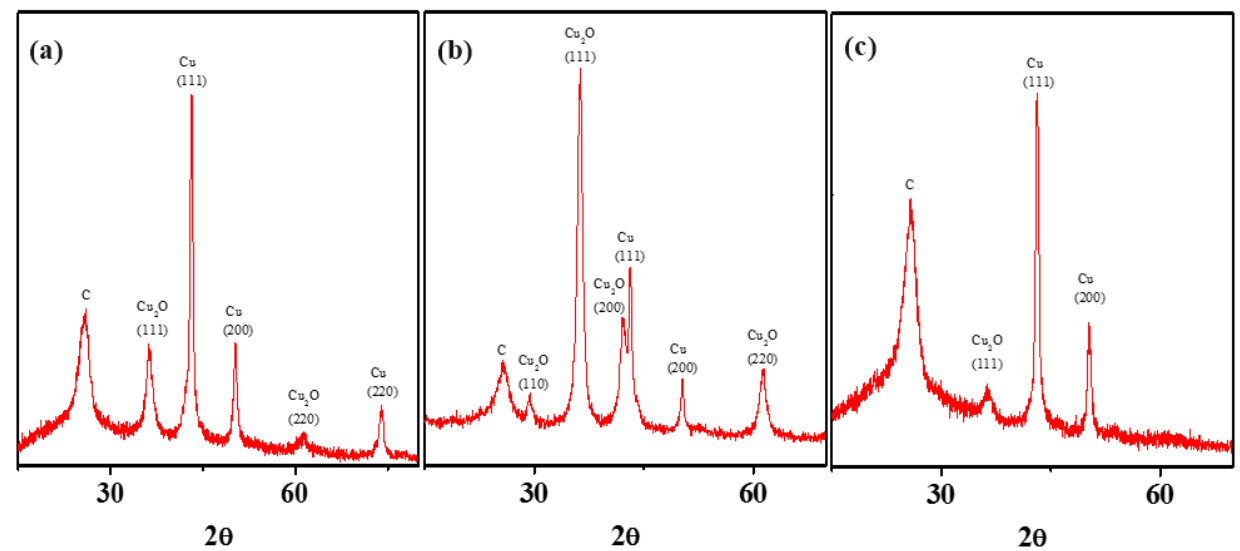

Figure 4. $\mathrm{XRD}$ spectrum of $\mathrm{MWNT}-\mathrm{Cu} / \mathrm{Cu}_{2} \mathrm{O} \mathrm{NH}$ synthesized using the sol-gel process (a) in isopropanol, (b) in oxygen-free conditions with isopropanol, and (c) in dimethylformamide (DMF). An airtight XRD sample holder was used for XRD analysis for all the three materials. The peak positions are labeled to indicate the respective crystal planes. The XRD spectra were collected at a scanning rate of $2^{\circ} / \mathrm{min}$. 
To facilitate zero-valent $\mathrm{Cu}$ formation on MWNTs, synthesis conditions were modified to avoid presence of ambient oxygen during the reaction (where, MWNT-isopropanol suspension was purged with nitrogen for $1 \mathrm{~h}$ and sampling handling was done in a glove box) and calcination processes. The synthesized NHs were also transferred into an airtight XRD sample holder to continue to avoid exposure to oxygen to the synthesized NHs. It is interesting to note that the nanocrystals formed in such anoxic reaction environment, continue to display $\mathrm{Cu}_{2} \mathrm{O}$ crystal planes, and with some additional $\mathrm{Cu}_{2} \mathrm{O}$ planes in higher intensity (Figure $4 \mathrm{~b}$ ). The results indicate that the likely oxidation of $\mathrm{Cu}$ has taken place, not during the XRD characterization, but likely during the synthesis process. The source of oxygen is likely $\mathrm{H}_{2} \mathrm{O}$ or $\mathrm{NO}_{3}{ }^{-}$, which could not be removed after the completion of the reaction process. These results indicate that the use of a reducing agent may be unavoidable for the lower magnitude SEP-metal Cu.

A solvent with a relatively higher reduction potential (compared to isopropanol), e.g., dimethyl formamide (DMF), can potentially facilitate formation of zero-valent $\mathrm{Cu}$ in a sol-gel synthesis; earlier studies have employed DMF for synthesizing Ag nanoparticles [63]. Following similar protocol as noted earlier (in typical oxic environment), the nanocrystals formed with the aid of DMF exhibit a lowering of the (111) $\mathrm{Cu}_{2} \mathrm{O}$ peak, while a complete elimination of the (220) peak observed earlier (Figure 4c). To assess the reducing potency of the solvents ORP can be measured. The isopropanol system has an ORP value of $+597 \mathrm{mV}$ compared to $\mathrm{DMF}^{\prime} \mathrm{s}+504 \mathrm{mV}$; which indicate a more conducive reducing environment when $\mathrm{DMF}$ is used [64]. These findings strongly suggest that formation of zero-valent crystals with a sol gel method may be challenging for metals with low magnitude SEP, and may necessitate stronger reducing environment to facilitate this process.

\section{Conclusions}

Sol-gel synthesis can be utilized to form both zero-valent and oxides of metals on MWNT surfaces. The resulting crystal phase is strongly dependent on the electronic properties of the metal species. The SEP, which is a measure of energy required per unit charge to drive a redox reaction, can be used as a guideline for the choice of metal to obtain nanocrystals with the desired crystalline phase. Results suggest that metals with higher SEP values form either zero-valent or oxide phases, while those with lower magnitude SEPs facilitate mixed-phase crystals. The sol-gel technique can be useful to form zero-valent crystals without any reducing agent; however, such a reducing environment may become necessary for oxidation-prone metals such as $\mathrm{Cu}$.

Supplementary Materials: The following are available online at http:/ /www.mdpi.com/2079-4991/8/6/403/s1.

Author Contributions: D.D. is the lead author of this article, who conducted the experiments, analyzed data, and played a central role in writing the manuscript. I.V.S. aided in data collection and analysis. T.S.-A. provided intellectual input in study design and manuscript preparation. N.B.S. led the study design, organized the manuscript outline, and finalized the manuscript text and data analyses.

Funding: This research was funded by the National Science Foundation, bearing grant number 1602273.

Acknowledgments: The authors thank Karalee Jarvis and Hugo Celio at the Texas Materials Institute for their assistance in electron microscopy and XPS analysis.

Conflicts of Interest: The authors declare no conflict of interest.

\section{References}

1. Eder, D.; Windle, A.H. Carbon-inorganic hybrid materials: The carbon-nanotube $/ \mathrm{TiO}_{2}$ interface. Adv. Mater. 2008, 20, 1787-1793. [CrossRef]

2. Alley, N.J.; Liao, K.S.; Andreoli, E.; Dias, S.; Dillon, E.P.; Orbaek, A.W.; Barron, A.R.; Byrne, H.J.; Curran, S.A. Effect of carbon nanotube-fullerene hybrid additive on P3HT:PCBM bulk-heterojunction organic photovoltaics. Synth. Met. 2012, 162, 95-101. [CrossRef]

3. Llobet, E.; Espinosa, E.; Sotter, E.; Ionescu, R.; Vilanova, X.; Torres, J.; Felten, A.; Pireaux, J.-J.; Ke, X.; Van Tendeloo, G. Carbon nanotube- $-\mathrm{TiO}_{2}$ hybrid films for detecting traces of $\mathrm{O}_{2}$. Nanotechnology 2008, 19, 375501. [CrossRef] [PubMed] 
4. Liu, Z.; Wang, J.; Xie, D.; Chen, G. Polyaniline-Coated $\mathrm{Fe}_{3} \mathrm{O}_{4}$ Nanoparticle-Carbon-Nanotube Composite and its Application in Electrochemical Biosensing. Small 2008, 4, 462-466. [CrossRef] [PubMed]

5. Zhu, Y.; Elim, H.I.; Foo, Y.L.; Yu, T.; Liu, Y.; Ji, W.; Lee, J.Y.; Shen, Z.; Wee, A.T.-S.; Thong, J.T.-L. Multiwalled carbon nanotubes beaded with $\mathrm{ZnO}$ nanoparticles for ultrafast nonlinear optical switching. Adv. Mater. 2006, 18, 587-592. [CrossRef]

6. Das, D.; Plazas-Tuttle, J.; Sabaraya, I.V.; Jain, S.S.; Sabo-Attwood, T.; Saleh, N.B. An elegant method for large scale synthesis of metal oxide-carbon nanotube nanohybrids for nano-environmental application and implication studies. Environ. Sci. Nano 2017, 4, 60-68. [CrossRef]

7. Lv, X.; Xu, J.; Jiang, G.; Xu, X. Removal of chromium(VI) from wastewater by nanoscale zero-valent iron particles supported on multiwalled carbon nanotubes. Chemosphere 2011, 85, 1204-1209. [CrossRef] [PubMed]

8. Ma, P.C.; Tang, B.Z.; Kim, J.-K. Effect of CNT decoration with silver nanoparticles on electrical conductivity of CNT-polymer composites. Carbon 2008, 46, 1497-1505. [CrossRef]

9. Rao, C.N.R.; Müller, A.; Cheetham, A.K. The Chemistry of Nanomaterials: Synthesis, Properties and Applications; John Wiley \& Sons: Hoboken, NJ, USA, 2006.

10. Rana, D.; Mandal, B.M.; Bhattacharyya, S.N. Analogue Calorimetric Studies of Blends of Poly(vinyl ester)s and Polyacrylates. Macromolecules 1996, 29, 1579-1583. [CrossRef]

11. Rana, D.; Mandal, B.M.; Bhattacharyya, S.N. Analogue calorimetry of polymer blends: Poly(styrene-co-acrylonitrile) and poly(phenyl acrylate) or poly(vinyl benzoate). Polymer 1996, 37, 2439-2443. [CrossRef]

12. Rana, D.; Mandal, B.M.; Bhattacharyya, S.N. Miscibility and phase diagrams of poly(phenyl acrylate) and poly(styrene-co-acrylonitrile) blends. Polymer 1993, 34, 1454-1459. [CrossRef]

13. Fokin, V.M.; Zanotto, E.D.; Schmelzer, J.W.P. On the thermodynamic driving force for interpretation of nucleation experiments. J. Non-Cryst. Solids 2010, 356, 2185-2191. [CrossRef]

14. Vorkapic, D.; Matsoukas, T. Effect of temperature and alcohols in the preparation of titania nanoparticles from alkoxides. J. Am. Ceram. Soc. 1998, 81, 2815-2820. [CrossRef]

15. Raveendran, P.; Fu, J.; Wallen, S.L. Completely "green" synthesis and stabilization of metal nanoparticles. J. Am. Ceram. Soc. 2003, 125, 13940-13941. [CrossRef] [PubMed]

16. He, F.; Zhao, D. Manipulating the size and dispersibility of zerovalent iron nanoparticles by use of carboxymethyl cellulose stabilizers. Environ. Sci. Technol. 2007, 41, 6216-6221. [CrossRef] [PubMed]

17. Bom, D.; Andrews, R.; Jacques, D.; Anthony, J.; Chen, B.; Meier, M.S.; Selegue, J.P. Thermogravimetric analysis of the oxidation of multiwalled carbon nanotubes: Evidence for the role of defect sites in carbon nanotube chemistry. Nano Lett. 2002, 2, 615-619. [CrossRef]

18. Mulfinger, L.; Solomon, S.D.; Bahadory, M.; Jeyarajasingam, A.V.; Rutkowsky, S.A.; Boritz, C. Synthesis and study of silver nanoparticles. J. Chem. Educ. 2007, 84, 322. [CrossRef]

19. Mo, C.B.; Cha, S.I.; Kim, K.T.; Lee, K.H.; Hong, S.H. Fabrication of carbon nanotube reinforced alumina matrix nanocomposite by sol-gel process. Mater. Sci. Eng. A 2005, 395, 124-128. [CrossRef]

20. Sun, J.; Gao, L.; Li, W. Colloidal processing of carbon nanotube/alumina composites. Chem. Mater. 2002, 14, 5169-5172. [CrossRef]

21. Kumari, L.; Zhang, T.; Du, G.; Li, W.; Wang, Q.; Datye, A.; Wu, K. Synthesis, microstructure and electrical conductivity of carbon nanotube-Alumina nanocomposites. Ceram. Int. 2009, 35, 1775-1781. [CrossRef]

22. Zhang, D.; Shi, L.; Fu, H.; Fang, J. Ultrasonic-assisted preparation of carbon nanotube/cerium oxide composites. Carbon 2006, 44, 2853-2855. [CrossRef]

23. Kalubarme, R.S.; Kim, Y.-H.; Park, C.-J. One step hydrothermal synthesis of a carbon nanotube/cerium oxide nanocomposite and its electrochemical properties. Nanotechnology 2013, 24, 365401. [CrossRef] [PubMed]

24. Lang, J.; Yan, X.; Xue, Q. Facile preparation and electrochemical characterization of cobalt oxide/multi-walled carbon nanotube composites for supercapacitors. J. Power Source 2011, 196, 7841-7846. [CrossRef]

25. Wang, G.; Shen, X.; Yao, J.; Wexler, D.; Ahn, J.-H. Hydrothermal synthesis of carbon nanotube/cobalt oxide core-shell one-dimensional nanocomposite and application as an anode material for lithium-ion batteries. Electrochem. Commun. 2009, 11, 546-549. [CrossRef]

26. Yang, H.; Zhang, D.; Shi, L.; Fang, J. Synthesis and strong red photoluminescence of europium oxide nanotubes and nanowires using carbon nanotubes as templates. Acta Mater. 2008, 56, 955-967. [CrossRef] 
27. Chuansheng, C.; Tiangui, L.; Xiaohua, C.; Bin, Y.; Zhenwu, N.; Zhenwu, N.; Can, Z.; Chenchong, H. Preparation of Multi-Walled Carbon Nanotubes/Europium Oxide Composite. Rare Met. Mater. Eng. 2009, 38, 477-480.

28. Chen, C.; Hu, J.; Shao, D.; Li, J.; Wang, X. Adsorption behavior of multiwall carbon nanotube/iron oxide magnetic composites for Ni (II) and Sr (II). J. Hazard. Mater. 2009, 164, 923-928. [CrossRef] [PubMed]

29. Hu, J.; Shao, D.; Chen, C.; Sheng, G.; Li, J.; Wang, X.; Nagatsu, M. Plasma-induced grafting of cyclodextrin onto multiwall carbon nanotube/iron oxides for adsorbent application. J. Phys. Chem. B 2010, 114, 6779-6785. [CrossRef] [PubMed]

30. Chen, C.; Wang, X.; Nagatsu, M. Europium adsorption on multiwall carbon nanotube/iron oxide magnetic composite in the presence of polyacrylic acid. Environ. Sci. Technol. 2009, 43, 2362-2367. [CrossRef] [PubMed]

31. Wang, Q.; Li, J.; Chen, C.; Ren, X.; Hu, J.; Wang, X. Removal of cobalt from aqueous solution by magnetic multiwalled carbon nanotube/iron oxide composites. Chem. Eng. J. 2011, 174, 126-133. [CrossRef]

32. Ikuno, T.; Yasuda, T.; Honda, S.-I.; Oura, K.; Katayama, M.; Lee, J.-G.; Mori, H. Coating carbon nanotubes with inorganic materials by pulsed laser deposition. J. Appl. Phys. 2005, 98, 114305. [CrossRef]

33. Ikuno, T.; Katayama, M.; Kamada, K.; Honda, S.-I.; Lee, J.-G.; Mori, H.; Oura, K. Insulator-coated carbon nanotubes synthesized by pulsed laser deposition. Jpn. J. Appl. Phys. 2003, 42, L1356. [CrossRef]

34. Pan, L.; Konishi, Y.; Tanaka, H.; Chakrabarti, S.; Hokushin, S.; Akita, S.; Nakayama, Y. Effect of MgO coating on field emission of a stand-alone carbon nanotube. J. Vacuum Sci. Technol. B 2007, 25, 1581-1583. [CrossRef]

35. Wang, Q.; Wen, Z.H.; Li, J.H. A hybrid supercapacitor fabricated with a carbon nanotube cathode and a $\mathrm{TiO}_{2}-\mathrm{B}$ nanowire anode. Adv. Funct. Mater. 2006, 16, 2141-2146. [CrossRef]

36. Roro, K.T.; Tile, N.; Mwakikunga, B.; Yalisi, B.; Forbes, A. Solar absorption and thermal emission properties of multiwall carbon nanotube/nickel oxide nanocomposite thin films synthesized by sol-gel process. Mater. Sci. Eng. B 2012, 177, 581-587. [CrossRef]

37. Wen, B.; Cao, M.-S.; Hou, Z.-L.; Song, W.-L.; Zhang, L.; Lu, M.-M.; Jin, H.-B.; Fang, X.-Y.; Wang, W.-Z.; Yuan, J. Temperature dependent microwave attenuation behavior for carbon-nanotube/silica composites. Carbon 2013, 65, 124-139. [CrossRef]

38. Sivakumar, R.; Guo, S.; Nishimura, T.; Kagawa, Y. Thermal conductivity in multi-wall carbon nanotube/silica-based nanocomposites. Scr. Mater. 2007, 56, 265-268. [CrossRef]

39. Bottini, M.; Tautz, L.; Huynh, H.; Monosov, E.; Bottini, N.; Dawson, M.I.; Bellucci, S.; Mustelin, T. Covalent decoration of multi-walled carbon nanotubes with silica nanoparticles. Chem. Commun. 2005, 6, 758-760. [CrossRef] [PubMed]

40. Wongchoosuk, C.; Wisitsoraat, A.; Tuantranont, A.; Kerdcharoen, T. Portable electronic nose based on carbon nanotube- $\mathrm{SnO}_{2}$ gas sensors and its application for detection of methanol contamination in whiskeys. Sens. Actuators B Chem. 2010, 147, 392-399. [CrossRef]

41. Woan, K.; Pyrgiotakis, G.; Sigmund, W. Photocatalytic Carbon-Nanotube-TiO 2 Composites. Adv. Mater. 2009, 21, 2233-2239. [CrossRef]

42. Ding, M.; Sorescu, D.C.; Star, A. Photoinduced Charge Transfer and Acetone Sensitivity of Single-Walled Carbon Nanotube-Titanium Dioxide Hybrids. J. Am. Chem. Soc. 2013, 135, 9015-9022. [CrossRef] [PubMed]

43. Wu, G.-M.; Wang, A.-R.; Zhang, M.-X.; Yang, H.-Y.; Zhou, B.; Shen, J. Investigation on properties of V2O5-MWCNTs composites as cathode materials. J. Sol Gel Sci. Technol. 2008, 46, 79-85. [CrossRef]

44. Green, J.M.; Dong, L.; Gutu, T.; Jiao, J.; Conley, J.F., Jr.; Ono, Y. ZnO-nanoparticle-coated carbon nanotubes demonstrating enhanced electron field-emission properties. J. Appl. Phys. 2006, 99, 094308. [CrossRef]

45. Sun, Z.; Zhang, X.; Na, N.; Liu, Z.; Han, B.; An, G. Synthesis of $\mathrm{ZrO}_{2}$-Carbon Nanotube Composites and Their Application as Chemiluminescent Sensor Material for Ethanol. J. Phys. Chem. B 2006, 110, 13410-13414. [CrossRef] [PubMed]

46. Gao, C.; Li, W.; Jin, Y.Z.; Kong, H. Facile and large-scale synthesis and characterization of carbon nanotube/silver nanocrystal nanohybrids. Nanotechnology 2006, 17, 2882. [CrossRef]

47. Rahman, G.; Guldi, D.M.; Zambon, E.; Pasquato, L.; Tagmatarchis, N.; Prato, M. Dispersable carbon nanotube/gold nanohybrids: Evidence for strong electronic interactions. Small 2005, 1, 527-530. [CrossRef] [PubMed]

48. Wu, B.; Kuang, Y.; Zhang, X.; Chen, J. Noble metal nanoparticles/carbon nanotubes nanohybrids: Synthesis and applications. Nano Today 2011, 6, 75-90. [CrossRef] 
49. Jawale, D.V.; Gravel, E.; Boudet, C.; Shah, N.; Geertsen, V.; Li, H.; Namboothiri, I.N.; Doris, E. Room temperature Suzuki coupling of aryl iodides, bromides, and chlorides using a heterogeneous carbon nanotube-palladium nanohybrid catalyst. Catal. Sci. Technol. 2015, 5, 2388-2392. [CrossRef]

50. Kecsenovity, E.; Endrődi, B.; Pápa, Z.; Hernádi, K.; Rajeshwar, K.; Janáky, C. Decoration of ultra-long carbon nanotubes with $\mathrm{Cu}_{2} \mathrm{O}$ nanocrystals: A hybrid platform for enhanced photoelectrochemical $\mathrm{CO}_{2}$ reduction. J. Mater. Chem. A 2016, 4, 3139-3147. [CrossRef]

51. Chen, L.; Tsang, S.C. Ag doped WO 3-based powder sensor for the detection of NO gas in air. Sens. Actuators B Chem. 2003, 89, 68-75. [CrossRef]

52. Sohrabi, M.R.; Mansouriieh, N.; Khosravi, M.; Zolghadr, M. Removal of diazo dye Direct Red 23 from aqueous solution using zero-valent iron nanoparticles immobilized on multi-walled carbon nanotubes. Water Sci. Technol. 2015, 71, 1367-1374. [CrossRef] [PubMed]

53. Afrooz, A.N.; Das, D.; Murphy, C.J.; Vikesland, P.; Saleh, N.B. Co-transport of gold nanospheres with single-walled carbon nanotubes in saturated porous media. Water Res. 2016, 99, 7-15. [CrossRef] [PubMed]

54. Aich, N.; Boateng, L.K.; Sabaraya, I.V.; Das, D.; Flora, J.R.; Saleh, N.B. Aggregation kinetics of higher order fullerene clusters in aquatic systems. Environ. Sci. Technol. 2016, 50, 3562-3571. [CrossRef] [PubMed]

55. Afrooz, A.N.; Khan, I.A.; Hussain, S.M.; Saleh, N.B. Mechanistic heteroaggregation of gold nanoparticles in a wide range of solution chemistry. Environ. Sci. Technol. 2013, 47, 1853-1860. [CrossRef] [PubMed]

56. Khan, I.A.; Afrooz, A.R.M.N.; Flora, J.R.V.; Schierz, P.A.; Ferguson, P.L.; Sabo-Attwood, T.; Saleh, N.B. Chirality affects aggregation kinetics of single-walled carbon nanotubes. Environ. Sci. Technol. 2013, 47, 1844-1852. [CrossRef] [PubMed]

57. Khan, I.A.; Aich, N.; Afrooz, A.R.M.N.; Flora, J.R.V.; Ferguson, L.; Sabo-Attwood, T.; Saleh, N.B. Fractal structures of single-walled carbon nanotubes in biologically relevant conditions: Role of chirality vs. media conditions. Chemosphere 2013, 93, 1997-2003. [CrossRef] [PubMed]

58. Khan, I.A.; Flora, J.R.V.; Afrooz, A.R.M.N.; Aich, N.; Schierz, P.A.; Ferguson, P.L.; Sabo-Attwood, T.; Saleh, N.B. Change in chirality of semiconducting single-walled carbon nanotubes can overcome anionic surfactant stabilisation: A systematic study of aggregation kinetics. Environ. Chem. 2015, 12, 652-661. [CrossRef] [PubMed]

59. Saleh, N.B.; Pfefferle, L.D.; Elimelech, M. Aggregation kinetics of multiwalled carbon nanotubes in aquatic systems: Measurements and environmental implications. Environ. Sci. Technol. 2008, 42, 7963-7969. [CrossRef] [PubMed]

60. Dai, K.; Chen, H.B.; Liu, C.W.; Chen, H.; Huang, Q.Y. Photocatalytic Degradation of Sulfonamides over the Short Multi-walled Carbon Nanotube-TiO 2 Hybrid. In Frontier of Nanoscience and Technology II; Kao, J.C.M., Hou, M., Chen, R., Eds.; Trans Tech Publications: Hong Kong, China, 2012; Volume 528, pp. 259-262.

61. Sun, Y.; Xia, Y. Shape-controlled synthesis of gold and silver nanoparticles. Science 2002, 298, 2176-2179. [CrossRef] [PubMed]

62. Ghodselahi, T.; Vesaghi, M.; Shafiekhani, A.; Baghizadeh, A.; Lameii, M. XPS study of the $\mathrm{Cu}_{\mathrm{C}} \mathrm{Cu}_{2} \mathrm{O}$ core-shell nanoparticles. Appl. Surface Sci. 2008, 255, 2730-2734. [CrossRef]

63. Pastoriza-Santos, I.; Liz-Marzán, L.M. Formation and stabilization of silver nanoparticles through reduction by N,N-dimethylformamide. Langmuir 1999, 15, 948-951. [CrossRef]

64. Ashby, M.T. Hypothiocyanite. In Advances in Inorganic Chemistry; Elsevier: New York, NY, USA, 2012; pp. 263-303.

(C) 2018 by the authors. Licensee MDPI, Basel, Switzerland. This article is an open access article distributed under the terms and conditions of the Creative Commons Attribution (CC BY) license (http://creativecommons.org/licenses/by/4.0/). 